numerous exciting follow-up studies in various wavelength regions will have to be performed.

\section{EXOSAT}

The European X-ray satellite EXOSAT was launched at the end of May, 1983. Although some of the experiments on board caused problems during a few weeks, it now appears that many scientific results are becoming available, as was evident from the session organized on this satellite.

Thirty two contributed papers gave a good impression of the productivity and exciting new, although preliminary, results from the first months of EXOSAT in orbit. Particular interest was shown in the new spectroscopic data on several hot white dwarf stars and galactic binaries. The ability to carry out long uninterrupted observations and to observe in real time were evidently valuable features of the highly eccentric EXOSAT orbit. Coming only a few months after the start of the main observing programme, the session in Florence underlined the great potential of EXOSAT for European astronomers over the next few years.

Several international conferences are being organized in 1984 on the subject of X-ray astronomy: no doubt many results will be presented based on purely EXOSAT data or on simultaneous observations with e.g. EXOSAT, IUE and ground-based telescopes.

\section{Atomic and Molecular Physics for As- tronomy}

The aim of this meeting was to bring together "producers" and "users" of atomic and molecular data and theories.

According to many participants, it was a real success. Three invited papers and 25 original contributions were presented in one day; they were distributed among different sub-sections: term analysis and transition probabilities for atoms (7 papers), molecular physics (7), basic processes (2), line broadening (3), highly-ionized atoms (6). It is through this type of meeting that astrophysicists learn to understand the problems physicists encounter, while physicists better realize what are the needs for data and the role they play in astrophysics. Such goals have undoubtedly been achieved during the Florence specialized meeting: the present astronomical needs for accurate atomic and molecular data have been stressed, and many physicists have reported on new data which rapidly respond to the requests from astrophysicists.

The meeting on Atomic and Molecular Physics for Astronomy was in fact a very good example of cross-fertilization between physicists and astrophysicists and therefore fulfils one of the main aims of joint EPS/IAU ventures.

The Eighth European Regional Astronomy Meeting will be held in Toulouse, France, from September 17 - 21, 1984: it should, as in Florence, be open to all astrophysical disciplines, and have, in addition the following four specialized sessions:

- high spatial resolution in solar physics;

- new aspects of galaxy photometry;

- near molecular clouds;

- physical processes near the Eddington limit.

The Ninth Meeting is then scheduled for 1986, and it is hoped that it will take place as a "European forum": the loca- tion of this gathering is expected to be defined later this year, once offers from host cities or institutions have been received by the EPS or the IAU.

The success of the Florence Meeting has given a strong impetus towards the creation of a European Astronomical Society: there is no doubt that the European astronomical community has indeed become sufficiently strong and mature, and that the creation of such a society would be most timely and appropriate. Contacts to this effect are presently taking place, and the results will be discussed at the time of the Toulouse gathering (see also page 3).

\section{Jean-Pierre Swings}

(Secretary, Astronomy and

Astrophysics Divisional Board)

\title{
CMD Section Committee Elections
}

Following the recent elections within the Sections of the Condensed Matter Division, the basic Committees are made up as follows. These Committees will be electing their own Chairmen and coopting additional members:

\section{Low Temperature Section}

M. Krusius, University, Turku

F. Pobell, KFA, Jülich

H. Postma, University, Delft

F.B. Rasmussen, H.C. Ørsted Inst., Copenhagen

D. Thoulouze, CRTB-CNRS, Grenoble

W.F. Vinen, University, Birmingham

Macromolecular Physics Section

F. Baltà-Calleja, Inst. of Chem. Physics, Madrid

G. Bodor, Polymer Res. Inst. Budapest

A. Keller, University, Bristol

H.G. Kilian, University, Ulm

J.P. Mercier, High Polymer Lab.,

Louvain-la-Neuve

L. Monnerie, ESPCI, Paris

\section{Magnetism Section}

L.J. de Jongh, Kammerlingh Onnes

Laboratory, Leiden

R. Elliott, University, Oxford

J. Kaczer, Czechoslovak Acad. of Sciences, Prague

G.M. Kalvius, Tech. University, Munich

E. Karlsson, University, Uppsala

S. Methfessel, Ruhr Univ., Bochum

\section{Metals Section}

D. Bacon, University, Liverpool

K.H.J. Buschow, Philips' Res. Labs.,

Eindhoven

R. Cahn, University, Cambridge

O. Fischer, University, Geneva

J.P. Gaspard, University, Liège

E. Lüscher, Technical University, Munich
Semiconductors and Insulators Section J.W. Allen, University, St. Andrews

D. Bäuerle, University, Linz

F. Beleznay, Inst. for Technical Physics, Budapest

R. Blinc, Josef Stefan Inst., Ljublijana

H. Grimmeiss, University, Lund

G. Harbeke, RCA Labs., Zurich

Surfaces and Interfaces Section

G. Benedek, University, Milan

F. Koch, Tech. University, Munich

B.I. Lundqvist, Chalmers Univ. of

Technology, Göteborg

F. Saris, FOM Inst. for Atomic and

Molecular Physics, Amsterdam

H.C. Siegmann, ETH, Zurich

R.F. Willis, Cavendish Labs., Cambridge

\section{Elections \\ to the Plasma Physics Board}

At the end of May, the Plasma Physics Division will be electing a new Board to serve for the next three years. This will consist of 12 full members (of whom at least six cannot have served on the present Board) and up to three co-opted members, all of whom resign at the end of their term. National societies and members of the Division are invited to nominate candidates. Those from the Division should carry the signatures of three Individual Ordinary Members and an assurance that the candidate is willing to serve if elected. Proposals should be sent by 18 May 1984 to the Chairman:

Dr. A. Gibson,

JET Joint Undertaking

Abingdon, OX14 3EA, England 